\title{
Optimization of Design Mix Proportion for Saturated Water Absorption of High Performance Concrete
}

\author{
M. Akila ${ }^{1}$ and S. Chithra ${ }^{2}$ \\ ${ }^{1}$ PG Student, Department of Structural Engineering, ${ }^{2}$ Assistant Professor,Department of Civil Engineering, \\ Government College of Technology, Coimbatore, Tamil Nadu, India \\ E-Mail: akila08ii@gmail.com, mail2chith@gmail.com
}

\begin{abstract}
This study involves the optimization of design mix proportion for saturated water absorption of high performance concrete (HPC) by Taguchi Method. In the present investigation, saturated water absorption test on 25 HPC mixes specimens made with colloidal nano silica and copper slag as replacement of cement and fine aggregate respectively has been conducted at the age of 28 days and 90 days of water curing. The concrete mixes has been replaced by $1 \%, 1.5 \%, 2 \%, 2.5 \%, 3 \%$ of nano silica and copper slag of $10 \%, 20 \%, 30 \%, 40 \%, 50 \%$. From Signal-to-Noise ratio, the optimal parametric combination for saturated water absorption has been obtained. The Analysis of Variance has been done on experimental data values. The percentage contribution of the factors towards saturated water absorption is identified. The nano silica contributes towards less water absorption in 28 days curing, while the Copper slag found to the major contributing factor for the cause after the 90 days tenure of water curing.
\end{abstract}

Keywords: High Performance Concrete, Nano Silica, Copper Slag, Optimization, Taguchi Method

\section{I.INTRODUCTION}

The immediate need for replacement of naturally available resource in the conventional concrete by potential industrial wastes, without compromising the original quality to an extent has been a potential area of research.According to American Concrete Institute (ACI), High performance concrete (HPC)is a concrete in which certain characteristics are developed for a particular application and environment, which possesses higher values of workability, strength and durability. HPC contains materials such as fly ash, Silica fume, GGBS, Carbon black powder, anhydrous gypsum based mineral additives and a super plasticizer enhances the strength, durability and workability. Normally, a small percentage of nano silica replacement is enough to enhance the properties of HPC[1].The concrete mixtureproportioning problem has become more tedious after the arrival of organic admixtures, supplementary cementitious materialssuch as fly ash, fillerand fibres [2].

Silica fume is found to enhance compressive strength by decreasing pore size and permeability from the earlier researches. Silica fume increases the performance of concrete involving the recycled aggregate the abrasion resistance values for the different target strengths has been achieved. Recycled aggregate concrete and conventional concrete shows asimilar value regardless of thereplacement ratio used in themix[3].Normal pozzolana additives, dueto their lowsurface area and reactivity are not able to improve earlystrengths and durability of concrete. The problem can be solved by using a mixture of normal and highly reactive pozzolana, such as condensed silica-fume [4].The water absorption and water exchange between RCA and new cement paste is thus found to be the reason. It is thus necessary to quantify the weight fraction of in-pore water, which is usually done through the so-called water absorption coefficient (WAC) [5]. The design of experiments using orthogonal arrays is quite efficient compared to traditional experiment design methods. The orthogonal array reduces the number of experiments and minimizes the parameters involved, reducing the time involved in initial mix setting.The Taguchi method organizes the factors that influences the process and also the levels of these factors need to be varied systematically which is necessary to complete the experiment with minimum trials in order to save the time, money and resources instead of performing[6].

The analytical method optimizes the program and reduces the number of trial mixes. Six sigma technique is a methodology used in optimization meant for producing intent results meant for process improvement. It uses a set of quality management methods, mainly empirical, statistical methods. A systematic approach is needed to apply the Taguchimethod to the solution of problems. [7]The Taguchi method reduces the number of experimental runs to a reasonable one, in terms of cost and time, by using orthogonal arrays. Taguchi method follows the six sigma technology. Taguchi method is a statistical method, also called as robust design methods, developed by Genichi Taguchi to improve the quality of manufactured goods, and more recently also applied to engineering, biotechnology, marketing and advertising. "Orthogonal Arrays" (OA) provide a set of well-balanced experiments and Taguchi's Signal-to-Noise ratios (SN), which are log functions of desired output, serve as objective functions for optimization, help in data analysis and prediction of optimum results. The Taguchi method uses a signal-to-noise ratio for optimization. The $\mathrm{SN}$ ratio helps in data analysis and prediction of optimum result. In effect, OA provides a set of sorted experimental results and SN ratio serves as one of the significant functional tool for optimization. 


\section{II.MATERIALS AND TESTING}

The ingredients used for the mix formulation is explained as follows: Ordinary Portland Cement of 53 grade as per IS 12269:1987 standards has been used. Sand of fineness modulus of 2.91 was used as the main fine aggregate and copper slag as replacement material. The sand used was well graded and conforms to zone II as per IS: 383-1970 norms [8], with a bulk density of $1780 \mathrm{~kg} / \mathrm{m}^{3}$. Copper slag used in the study conforms to zone II and they meet the specification requirements. Crushed granite coarse aggregate of maximum size 12.5 has been used in this study. Ordinary tap water available in the laboratory was used for making mixes. A polycarboxylic ether based superplasticizer Glenium B233 conforming to IS 9103: 1999 has been added. Commercial type aqueous colloidal nano silica solution with a specific gravity between 1.3 and 1.32 has been used.

\section{A. Saturated Water Absorption Test}

The Saturated Water Absorption (SWA) tests of HPC mixes has been experimented on $100 \mathrm{~mm}$ cube specimens as per ASTM C642 at the age of 28 and 90 days. The weight of the samples has been weighed before drying. The drying was carried out in a hot air oven at a temperature of 105 degree centigrade. The drying process was continued until the difference in mass between two successive measurements at 24 hours interval agreed closely. The dried specimens were cooled to room temperature and then immersed in water. The specimens were taken out of water at regular intervals of time, surface dried using a clean cloth and weighed. This process has been continued till the weights became constant (fully saturated). The weights have been noted meticulously. The difference between the measured water saturated mass and oven dry mass expressed as a percentage of oven dry mass gives the saturated water absorption. The water absorption was calculated as

$$
\text { Percentage water absorption }=\frac{\mathrm{Ws}-\mathrm{Wd}}{\mathrm{Wd}} * 100(1)
$$

Where,

$\mathrm{W}_{\mathrm{s}}=$ weight of the specimen at fully saturated condition,

$\mathrm{W}_{\mathrm{d}}=$ weight of oven dried specimen.

\section{TAGUCHI METHOD}

\section{A. Analytical Analysis}

The experimental percentage values of the factors determine the number of levels. The ranges and levels of the parameters were selected in a way to represent the best possible compositions based on the presented compositions in the literature [9].There are five levels assigned for each factors in the analytical study (Table I). The upper and lower limits are derived based on the literature study for the High performance concrete with optimum Copper slag and Nano silica percentages. Based on the DOE $\mathrm{L}_{25}$ design has been adopted and explained in Table II.

TABLE I NUMBER OF LEVELS AND THEIR PERCENTAGE

\begin{tabular}{|c|c|c|}
\hline Level Number & $\begin{array}{c}\text { Percentage of } \\
\text { Nano silica }\end{array}$ & $\begin{array}{c}\text { Percentage of } \\
\text { Copper slag }\end{array}$ \\
\hline 1 & 1 & 10 \\
\hline 2 & 1.5 & 20 \\
\hline 3 & 2 & 30 \\
\hline 4 & 2.5 & 40 \\
\hline 5 & 3 & 50 \\
\hline
\end{tabular}

A five level $\left(\mathrm{L}_{25}\right)$ orthogonal array has been formulated based on the Taguchi design using MINITAB18. The orthogonal array allows to consider a selected subset of combinations of multiple factors at multiple levels. Based on the combinations with level 5, the following array is analysed in the Table II.

TABLE II ORTHOGONAL ARRAYS AND THEIRSUBSETS

\begin{tabular}{|c|c|c|c|}
\hline $\begin{array}{c}\text { Trial } \\
\text { Number }\end{array}$ & \multicolumn{3}{|c|}{ Factors And Their Levels } \\
\hline & A & B & C \\
\hline 1 & 1 & 1 & 1 \\
\hline 2 & 1 & 2 & 2 \\
\hline 3 & 1 & 3 & 3 \\
\hline 4 & 1 & 4 & 4 \\
\hline 5 & 1 & 5 & 5 \\
\hline 6 & 2 & 1 & 2 \\
\hline 7 & 2 & 2 & 3 \\
\hline 8 & 2 & 3 & 4 \\
\hline 9 & 2 & 4 & 5 \\
\hline 10 & 2 & 5 & 1 \\
\hline 11 & 3 & 1 & 3 \\
\hline 12 & 3 & 2 & 4 \\
\hline 13 & 3 & 3 & 5 \\
\hline 14 & 3 & 4 & 1 \\
\hline 15 & 3 & 5 & 2 \\
\hline 16 & 4 & 1 & 4 \\
\hline 17 & 4 & 2 & 5 \\
\hline 18 & 4 & 3 & 1 \\
\hline 19 & 4 & 4 & 2 \\
\hline 20 & 4 & 5 & 3 \\
\hline 21 & 5 & 1 & 5 \\
\hline 22 & 5 & 2 & 1 \\
\hline 23 & 5 & 3 & 2 \\
\hline 24 & 5 & 4 & 3 \\
\hline 25 & 5 & 5 & 4 \\
\hline & & & \\
\hline
\end{tabular}

Mix details for the experiment showing the trials and their parametric composition is shown in the Table III. The materials are sieved as per the IS norms. 
TABLE IIIPARAMETER QUANTITY AND WATER ABSORPTION VALUE

\begin{tabular}{|c|c|c|c|c|c|c|}
\hline $\begin{array}{c}\text { Trial } \\
\text { Number }\end{array}$ & $\begin{array}{l}\text { Percentage of } \\
\text { Nano silica }\end{array}$ & $\begin{array}{l}\text { Percentage of } \\
\text { copper slag }\end{array}$ & $\begin{array}{c}\text { Nano silica } \\
\left(\mathrm{kg} / \mathrm{m}^{3}\right)\end{array}$ & $\begin{array}{c}\text { Fine Aggregate } \\
\left(\mathrm{kg} / \mathrm{m}^{3}\right)\end{array}$ & $\begin{array}{l}\text { Saturated water } \\
\text { absorption in } \\
\text { Percentage after } \\
28 \text { Days of curing }\end{array}$ & $\begin{array}{l}\text { Saturated water } \\
\text { absorption in } \\
\text { Percentage after } \\
90 \text { Days of curing }\end{array}$ \\
\hline 1 & 0.5 & 10 & 2.58 & 60.1 & 2.95 & 2.22 \\
\hline 2 & 0.5 & 20 & 2.58 & 120.2 & 2.77 & 2.09 \\
\hline 3 & 0.5 & 30 & 2.58 & 180.3 & 2.58 & 1.94 \\
\hline 4 & 0.5 & 40 & 2.58 & 240.4 & 2.43 & 1.85 \\
\hline 5 & 0.5 & 50 & 2.58 & 300.5 & 2.55 & 1.91 \\
\hline 6 & 1 & 10 & 5.16 & 60.1 & 2.72 & 2.05 \\
\hline 7 & 1 & 20 & 5.16 & 120.2 & 2.55 & 1.93 \\
\hline 8 & 1 & 30 & 5.16 & 180.3 & 2.58 & 1.94 \\
\hline 9 & 1 & 40 & 5.16 & 240.4 & 2.19 & 1.7 \\
\hline 10 & 1 & 50 & 5.16 & 300.5 & 2.35 & 1.77 \\
\hline 11 & 1.5 & 10 & 7.74 & 60.1 & 2.41 & 1.85 \\
\hline 12 & 1.5 & 20 & 7.74 & 120.2 & 2.28 & 1.74 \\
\hline 13 & 1.5 & 30 & 7.74 & 180.3 & 2.19 & 1.64 \\
\hline 14 & 1.5 & 40 & 7.74 & 240.4 & 1.95 & 1.52 \\
\hline 15 & 1.5 & 50 & 7.74 & 300.5 & 2.02 & 1.6 \\
\hline 16 & 2 & 10 & 10.32 & 60.1 & 2.48 & 1.89 \\
\hline 17 & 2 & 20 & 10.32 & 120.2 & 2.35 & 1.83 \\
\hline 18 & 2 & 30 & 10.32 & 180.3 & 2.26 & 1.71 \\
\hline 19 & 2 & 40 & 10.32 & 240.4 & 2.09 & 1.62 \\
\hline 20 & 2 & 50 & 10.32 & 300.5 & 2.21 & 1.69 \\
\hline 21 & 2.5 & 10 & 12.9 & 60.1 & 2.58 & 1.99 \\
\hline 22 & 2.5 & 20 & 12.9 & 120.2 & 2.46 & 1.89 \\
\hline 23 & 2.5 & 30 & 12.9 & 180.3 & 2.26 & 1.71 \\
\hline 24 & 2.5 & 40 & 12.9 & 240.4 & 2.13 & 1.64 \\
\hline 25 & 2.5 & 50 & 12.9 & 300.5 & 2.31 & 1.73 \\
\hline
\end{tabular}

TABLE IV ANALYSIS OF VARIANCE

\begin{tabular}{|c|c|c|c|c|c|c|c|}
\hline Source & DF & Seq SS & $\begin{array}{c}\text { Factor } \\
\text { Contribution }\end{array}$ & Adj SS & Adj MS & F-Value & P-Value \\
\hline \multicolumn{8}{|c|}{ Analysis of 28 Days cured specimens } \\
\hline NS & 4 & 0.70564 & $50.51 \%$ & 0.70564 & 0.176410 & 64.44 & 0.000 \\
\hline CS & 4 & 0.64756 & $46.35 \%$ & 0.64756 & 0.161890 & 59.14 & 0.000 \\
\hline Error & 16 & 0.04380 & $3.14 \%$ & 0.04380 & 0.002738 & & \\
\hline Total & 24 & 1.39700 & $100.00 \%$ & & & & \\
\hline \multicolumn{8}{|c|}{ Analysis of 90 Days cured specimens } \\
\hline NS & 4 & 0.32468 & $46.99 \%$ & 0.32468 & 0.081170 & 65.46 & 0.000 \\
\hline CS & 4 & 0.34648 & $50.14 \%$ & 0.34648 & 0.086620 & 69.85 & 0.000 \\
\hline Error & 16 & 0.01984 & $2.87 \%$ & 0.01984 & 0.001240 & & \\
\hline Total & 24 & 0.69100 & $100.00 \%$ & & & & \\
\hline
\end{tabular}

DF: degrees of freedom; Adj SS: adjusted sum of squares; Adj MS: adjusted mean squares; Seq SS: Sequential sum of squares;

NS\% : Percentage of Nano silica; CS\% :Percentage of copper slag 


\section{RESULTS AND DISCUSSION}

\section{A. Analysis of Variance}

The ANOVA table is formed by the Minitab based on the DOE values. The factor's Degree of Freedom (DF), Adjusted Sum of squares is evaluated by the software. Based on the Sum of squares the contribution Percentage has been calculated. The contribution Percentage indicates the individual factor contribution towards the saturated water absorption. The Table IV and V shows the results of the ANOVA where the analysis has been proceeded with the confidence level of $95 \%$. Sources with a p-value less than 0.05 were considered to have a statistically significant contribution to the performance measures. The following tables indicate the ANOVA values for 28 and 90 days respectively.From the table 4 , it has been found that in the 28 days cured specimen nano silica shows to be major factor for saturated water absorption. While the contribution percentage of copper slag is contributing more at the end of the 90 days curing towards water absorption.

\section{B. Sound to Noise Ratio (SN) Curves}

Involving the different factors, the Sound to noise ratio has been calculated for the saturated water absorption of the material.

Where,

$$
\mathrm{S} / \mathrm{N}=-10 \log 10(1 / \mathrm{n}) \Sigma(\mathrm{yi} 2)
$$

$\mathrm{n}$ is the number of observed values, and

$\mathrm{y}$ is the observed numerical data

The SN ratios and the response were plotted for each factor against each of its levels with a smaller-the-better condition forwear loss [10].The sound to Noise ratio denotes the error values and the unaccounted noise in the process. The SN ratio for the predictors Nano silica (NS), Copper slag (CS), with varying level values is explained in the Figure 1 . The mix with $2 \%$ of Nano silica and Copper slag content of $40 \%$ showsthe optimum value for the minimum saturated water absorption.

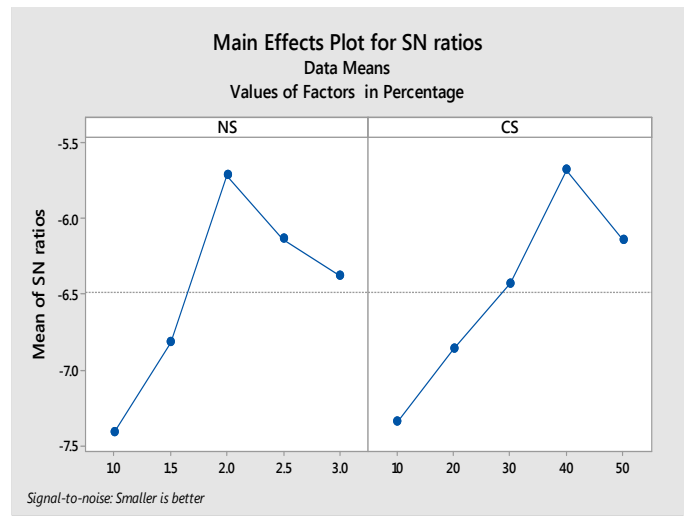

Fig. 1 SN Ratios for Mean Values

\section{CONCLUSION}

In this study it is aimed to optimize the design mix proportion for the saturated water absorption of High Performance Concrete (HPC). The design mix has been studied and the parameters contributing for the saturated water absorption measurement have been evaluated. The mathematical modelling has been done with the confidence level of $95 \%$. The statistical model provides the necessary modelling conditions for the design mix and proposes optimum conditions for the modelling. From the Analysis of Variance, nano silica is the dominant contribution factor for 28 days water curing contributing $50.51 \%$, copper slag has been found to be most significant factor in against the saturated water absorption of the HPC for 90 days water cured specimens, with the contributing percentage of 50.14\%. From Signal-to-Noise ratio, the optimal parametric combination for saturated water absorption has been obtained at the parametric combination of nano silica $2 \%$, copper slag $40 \%$ and Experimental errors for the 28 days and 90 days the saturated water absorption values were found to be smaller.

\section{REFERENCES}

[1] S. Chithra, S.R. R. Senthil Kumar and K. Chinnaraju, "The Effect of Colloidal Nano-silica on Workability, Mechanical and Durability Properties of High Performance Concrete with Copper Slag as Partial Fine Aggregate”,Construction and Building Materials, Vol. 113, pp. 794-804, 2016

[2] Francois de Larrard and Thierry Sedran, "Mixture-proportioning of High-Performance Concrete”, Cement and Concrete Research, Vol. 32, pp. 1699-1704, 2002

[3] AimanYacoub, Assia Djerbi and Teddy Fen-Chong, "Water Absorption in Recycled Sand: New Experimental Methods to Estimate the Water Saturation Degree and Kinetic Filling During Mortar Mixing”, Construction and Building Materials, Vol. 158, pp. 464-471, 2018.

[4] M. Quattrone B. Cazacliu, S.C. Angulo, E. Hamard and A. Cothenet, "Measuring the water absorption of recycled aggregates, what is the bestpractice for concrete production",Construction and Building Materials,Vol. 123, pp. 690-703, 2016.

[5] N. Naresh, K. Rajasekhar and P. VijayaBhaskara Reddy, "Parametric Analysis of GFRP Composites in CNC Milling Machine using Taguchi Method",IOSR Journal of Mechanical and Civil Engineering, e-ISSN: 2278-1684, Vol. 6, pp. 102-111, Issue 1, 2013.

[6] Ahmet Hayrullah Sevinc and Muhammed YasinDurgun,"Taguchi Approach for Investigating the Engineering Properties of Concretes Incorporating Barite, Colemanite, Basaltic Pumice and Ground Blast Furnace Slag",Construction and Building Materials, Vol. 135 pp. 343-351, 2017.

[7] Ahmer Ali siyal, KhairunAziziAzizli, Zakaria Man and HaffezUllah, "Effects of Parameters on the Setting Time of Fly Ash based Geopolymers by Taguchi Method”,Procedia Engineering,Vol. 148, pp. $302-307,2016$.

[8] IS: 383-1970, Specification for coarse and fine aggregates from natural sources for concrete, Bureau of Indian Standards, New Delhi, India

[9] Ankur Mehta, Rafatsiddigque, BahnuPratapsingh, SalimaAgggoun, Grzegorz Lagod and Danuta Barnat-Hunek, "The Influence of Various Parameters on Strength and Absorption Properties of Fly Ash based Geopolymer Concrete by Taguchi Method”, Construction and Building Materials, Vol. 150, pp. 817-824, 2017.

[10] Harun Tanyildizi and Murat Sahin, "Taguchi Method for Optimization of Concrete Strengthened with Polymer after High Temperature”,Construction and Building Materials, Vol. 79, pp. 97103, 2015. 